\title{
Diabetes and myocardial infarction: revisiting the conundrum!
}

\section{Mini review}

The idea of Diabetes Mellitus as a Myocardial infarction (MI) equivalent was first postulated by Haffner et al in their seminal article twenty years back. ${ }^{1}$ and was reaffirmed again in 2005 by Juutilainen et $a .^{2}$ Although recent studies have challenged the concept,,$^{3-4}$ the is no confusion as to the pivotal role of diabetes in driving coronary artery disease (CAD) and diabetes remains one of the most important risk factor for developing CAD. Not only diabetic patients have more prevalence of coronary artery disease, it is clearly more extensive too. ${ }^{5}$ Unfortunately, mortality rates with acute coronary syndromes in such patients is 1.5-2 times higher than non diabetic cohorts. ${ }^{6}$ Increased incidence of congestive heart failure, decreased vasodilatory reserve of coronary tree, abnormal myocardial metabolism, endothelial dysfunction, altered platelet reactivity and elevated reinfarction rates are putative causative elements. Nevertheless, diminished pain perception may lead to episodes of so called "silent infarction" or atypical symptoms causing delayed presentation to emergency department, both leading to delay in timely reperfusion in STEMI.

Establishment of prompt reperfusion of infarct related artery remains the goal in STEMI management. ST segment resolution is rapid and inexpensive tool to assess efficacy of reperfusion therapy in STEMI at bedside. ${ }^{7}$ Various studies have also documented the poor prognosis associated with non resolution of ST segment following thrombolysis. ${ }^{8} 9$ Thrombolytic therapy fails to achieve effective reperfusion in diabetic subset even in a setting of early presentation. ${ }^{10}$

In resource poor developing countries the goal of Primary PCI for all STEMI patients remains elusive. Recently, the STREAM trial investigators have shown non inferiority of a pharmacoinvasive strategy compared to Primary PCI. ${ }^{11}$ Even then transferring all patients to PCI capable centers after thrombolytic would impose a huge financial and logistic challenge. Then how to triage patients for a pharmacoinvasive approach? In light of the previous discussion, it suffices to say that Diabetic patients irrespective of ST segment resolution status and STEMI patients without ST segment resolution or partial resolution after an initial thrombolytic should be primarily candidates for this approach. Even in a pharmacoinvasive approach, use of a third generation fibrin specific fibrinolytic for a diabetic patient is preferable to achieve an early reperfusion enabling the diminished risk during transfer.

However the story does not end here. Diabetes also remains a predictor of adverse events in setting of PCI in acute MI. Diabetes remains a primary mechanism for "Slow flow" or "No reflow" phenomenon in acute coronary syndrome with consistent role in adverse outcomes. ${ }^{13}$ Diabetes mellitus also predicts increased risk of stent thrombosis after percutaneous coronary intervention in the setting of acute MI. ${ }^{12}$ Etiology of stent thrombosis is multifactorial including diffuse disease, low calibre vessels and altered platelet as well as endothelial function.

A pragmatic approach is needed for management of acute MI in diabetes. Use of potent third generation fibrinolytic like tenecteplase would be an initial step in the cascade. Novel anti platelet agent
Volume 5 Issue 5 - 2018

\author{
Akshyaya Pradhan, Rishi Sethi \\ Department of Cardiology, King George's Medical University, \\ India
}

Correspondence: Akshyaya Pradhan, Department of Cardiology, King George's Medical University, India, Tel +9 | 8400813739,Email akshyaya33@gmail.com

Received: October 01, 2018 | Published: October 08, 2018

Prasugel has been to reduce stent thrombosis and mortality in diabetes with STEMI. ${ }^{14}$ Parenteral Glycoprotein IIb/IIIa antagonist and thrombus aspiration are useful for prevention and treatment of slow flow. ${ }^{15}$ Third generation thin strut drug eluting stents have reduced both acute thrombosis and late restenosis too. ${ }^{16}$ High dose statins and other drugs for secondary prevention also improve outcomes.

To summarize, diabetes remains a high risk if not equivalent condition for development of Myocardial infarction. Appropriate selection of treatment strategies is need of hour to mitigate the risk associated with it.

\section{Acknowledgements}

None.

\section{Conflict of interest}

The author declares that there is no conflict interest.

\section{References}

1. Haffner SM, Lehto S, Rönnemaa T, et al. Mortality from coronary heart disease in subjects with type 2 diabetes and in nondiabetic subjects with and without prior myocardial infarction. N Engl J Med. 1998;339(4):229234.

2. Juutilainen A, Lehto S, Rönnemaa T, et al. Type 2 diabetes as a "coronary heart diseas equivalent": an 18-year prospective population-based study in Finnish subjects. Diabetes Care. 2005;28(12):2901-2907.

3. Bulugahapitiya U, Siyambalapitiya S, Sithole J, et al. Is diabetes a coronary risk equivalent? Systematic review and meta-analysis. Diabet Med. 2009;26(2):142-148.

4. Boyko EJ, Meigs JB. Does Diabetes Always Confer Coronary Heart Disease Risk Equivalent to a Prior Myocardial Infarction? Implications for prevention. Diabetes Care. 2011;34(3):782-784.

5. Jacoby R, Nesto R. Acute myocardial infarction in the diabetic patient: pathophysiology, clinical course and prognosis. J Am Coll Cardiol. 1992;20(3):736-744.

6. Aronson D, Rayfield E, Cheseboro J. Mechanisms determining course and outcome of diabetic patients who have had acute myocardial infarction. Ann Intern Med. 1997;126(4):296-306.

7. Schröder R. Prognostic Impact of Early ST-Segment Resolution in Acute ST-Elevation Myocardial Infarction. Circulation. 2004;110:506-510. 
8. Bhatia L, Clesham GJ, Turner DR. Clinical implications of ST-segment non-resolution after thrombolysis for myocardial infarction. $J$ R Soc Med. 2004;97:566-570.

9. de Lemos JA, Braunwald E. ST segment resolution as a tool for assessing the efficacy of reperfusion therapy. J Am Coll Cardiol. 2001;38(5):12831294.

10. Zairis M, Handanis SM, Lyras AG, et al. Type 2 Diabetes and Intravenous Thrombolysis Outcome in the Setting of ST Elevation Myocardial Infarction. Diabetes Care. 2004;27(4):967-971.

11. Armstrong PW, Gershlick AH, Goldstein P, et al. Fibrinolysis or primary PCI in ST-segment elevation myocardial infarction. $N$ Engl $J$ Med. 2013;368:1379-1387.

12. Dangas GD, Caixeta A, Meheran R, et al. Frequency and predictors of stent thrombosis after percutaneous coronary intervention in acute myocardial infarction. Circulation. 2011(16);123:1745-1756.
13. Jaffe R, Charron T, Puley G, et al. Micro vascular Obstruction and the No-Reflow Phenomenon After Percutaneous Coronary Intervention. Circulation. 2008;1179(24):3152-3156.

14. Wiviott SD, Braunwald E, Angilillo DJ, et al. Greater clinical benefits of more intensive oral antiplatelets with prasugrel in patients with diabetes mellitus in the trial to assess improvement in therapeutic outcomes by optimizing platelet inhibition with prasugrel- Thrombolysis in Myocardial infarction 38. Circulation. 2008(16);118:1626-1636.

15. Jaffe R, MD, Dick A, Strauss BH. Prevention and Treatment of Microvascular Obstruction-Related Myocardial Injury and Coronary NoReflow Following Percutaneous Coronary Intervention- A Systematic Approach. J Am Coll Cardiol Intv. 2010;3(7):695-704.

16. Palmerini T, Biondi-Zoccai G, Duella Riva D, et al. Clinical outcomes with drug eluting and bare metal stents in patients in with ST segment elevation myocardial infarction : evidence from a network meta-analysis. J Am Coll Cardiol. 2013;62:496-504. 